\title{
Energy Equalization Module for Modular Multilevel Converters in Variable Speed Motor Drives
}

\author{
Mohammad Sleiman ${ }^{\dagger}$, Mohamad Koteich ${ }^{\ddagger}$, Handy Fortin Blanchette ${ }^{\dagger}$, Hadi Kanaan ${ }^{\S}$ and Kamal Al-Haddad ${ }^{\dagger}$ \\ $\dagger$ Ecole de Technologie Supérieure, 1100 Rue Notre-Dame West, Montreal, Quebec, H3C 1K3, Canada \\ Email: mohammad.sleiman.1@ens.etsmtl.ca \\ $\ddagger$ Renault Group, Technocentre, 78288 Guyancourt, Paris Area, France \\ E-mail: mohamad.koteich@ renault.com \\ $\S$ Saint-Joseph University, Faculty of Engineering ESIB, CTS, Mar Roukoz, Mkalles, Lebanon
}

\begin{abstract}
Modular Multilevel Converters (MMC) processing phase quantities at low frequency are vulnerable to high cell voltage ripples. MMC upper and lower arms processes pulsating power at fundamental and second harmonic phase components. As a consequence, arms are expected to buffer the energy difference exchanged between DC-link and each AC-phase. This buffered energy is translated into increased cell voltage ripple when operating at low phase frequency. Several remedies have been presented in literature, which can be classified under software and hardware methods. To address this short-come we introduced a plug-in hardware alternative that permit energy exchange between cells from upper and lower arms thus remarkably reducing capacitor voltage ripples caused by out of phase energy variations. The proposed method can improve MMC performance over the full operation region and is mainly attractive to low frequency operation such as in variable-speed motor drives where higher-than-nominal torques might be required for a wide speed range. Performed simulations over a synchronous machine using maximum torque per current control technique, conforms well with the analytical findings and shows the effectiveness of the proposed method.
\end{abstract}

\section{INTRODUCTION}

The attractiveness of the Modular Multilevel Converter (MMC) topology lays behind a huge advancement it brought to the world of high power high voltage converters, as compared to classical multilevel converters such as the NPC, FC, and CHB [1]-[4] MMCs have shown superior features in terms of modularity, voltage $\backslash$ power scalability, high efficiency, and redundancy. Since it was first introduced in 2002 [5], [6], MMCs have been massively addressed in literature as an attractive competitor in the well-established high power converters world. It was not long until MMC was adopted by industries in HVDC systems [7], and medium voltage drive applications [8]. High power driving demand at high voltage, such as in variable speed AC drives used in pumps, conveyors, compressors, fans, blowers, mills, and propulsion, promotes MMCs to be the preferred next generation drive technology.

MMCs unlike classical medium and high power converters has a unique operating principles. As arm currents for example are continuous and energy is buffered in capacitor cells during power flow operation between the dc-side and the ac-side. As a consequence, arm cells have to synthesize dc-and ac-voltages while accommodating dc-and ac-current flow. This operational feature render arms to process average power to keep the cell average voltage constant, as well as pulsating power at the first and second harmonics of the MMC phase current frequencies. This power ripple behavior will eventually translate to capacitor voltages in upper and lower arms of the same phase, with its main ripple spectrum similar to the one of ripple power. In addition, symmetrical structure $\backslash$ operation of MMCs, will yield upper and lower arms per leg experiencing out-of-phase power ripple at the first harmonic, and in-phase power ripple at the second harmonic. Therefore, for a system with well-balanced cells, out-of-phase voltage ripples can be exchanged between two selected cells from upper and lower arms, whereas in-phase voltage ripples can be equally shared. For this task, we introduce a plug-in module that connects two cell capacitors together. The proposed plug-in module is an isolated-bidirectional dc-dc Dual Active half-Bridge (DAhB) capable of equalizing the instantaneous voltage ripple between the two capacitors. Dominant voltage ripples are inherently out-of-phase which can be canceled out, thus, such voltages equalization will impressively reduce voltage ripple across capacitors and hence render massive reduction in capacitor sizing requirements.

\section{Modular Multilevel Converters}

The introduction of Modular topologies for high voltage and power applications has over-performed classical bulky voltage-source converters. A recent topology in this category is the MMC, shown in (Fig. 1-b)) with n-legs. In MMC, power flow between input and output systems is controlled by MMC arms, formed of $N$ connected Half-Bridges in cascade, and acting as energy buffers, as well as current-source voltage-controlled synthesizers, capable of shaping reference phase voltages necessary to induce reference load currents.

As in single-phase ac-dc rectifiers, phase pulsating power is also seen in MMC arms, thus, irrespective of MMC legs' number connected to the dc-link, load phase power is composed of $\mathrm{dc}$ and second harmonic ac components. To the contrary, a constant power exchange type of behavior will be seen between MMC legs and dc-link. Therefore, load oscillating power has to be compensated by the arms, and this can explains voltage ripple seen in cell capacitors.

Hence, interactions between currents and voltages in an arm at two different frequencies will shape the power flow, and consequently define the energy variations within cells. The following analysis is therefor valid for any MMC structure and unconstrained with the cell topology neither with their count per arm. 


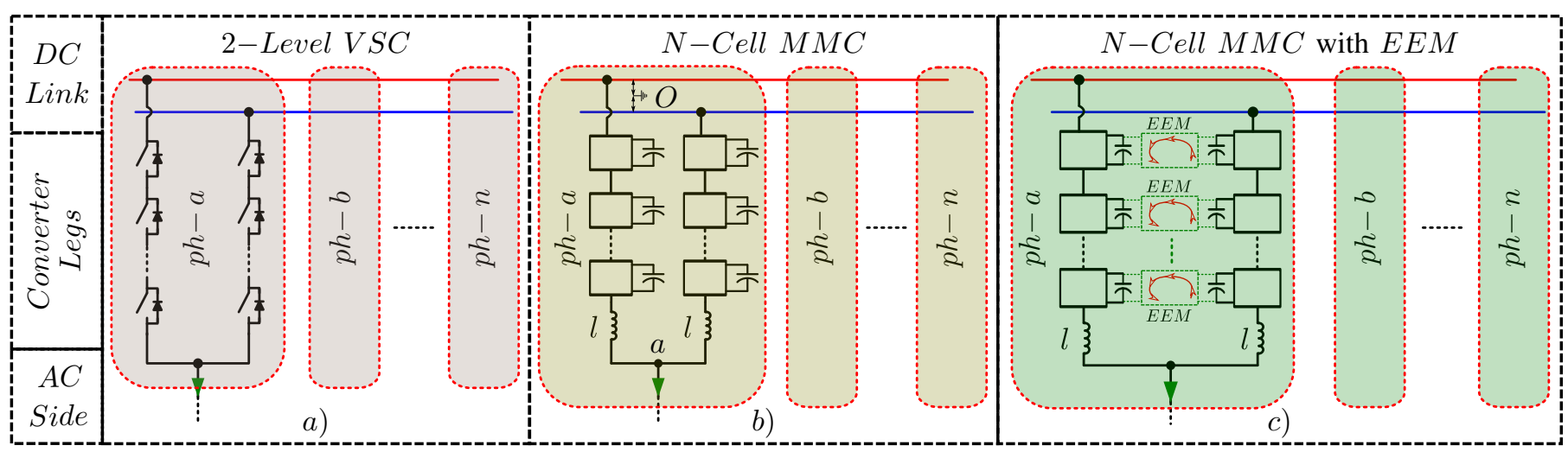

Fig. 1. High voltage topology evolution: a) Classical 2-Level Voltage Source Converter (VSC). b) Classical MMC. c) MMC with Energy Equalization Modules (EEM)

\section{A. Energy Variations in MMC Arms}

In n-ph MMC systems, analysis of one MMC leg with the dc-link can cover the power exchange behavior between the dc- and ac-system. Thus, in this study we will just consider one MMC leg.

In this analysis we assume no contribution of circulating currents from other legs and comparably high switching frequency along with large number of cells, hence voltage and current quantities at the phases can be described as,

$$
v_{y}=\hat{V}_{y} \sin (\omega t) \text { and } i_{y}=\hat{I}_{y} \sin (\omega t-\varphi)
$$

The desired currents in upper and lower arms will contain a dc current component $\left(I_{x}\right)$ from dc-link and a $50 \%$ contribution of phase current $i_{y}$. Thus the upper and lower arm currents can be expressed as,

$$
i_{1,2}=I_{x} \pm \frac{1}{2} i_{y}
$$

where subscripts $(1,2)$ points to arms 1 and 2 respectively. For this we consider an MMC phase voltage being synthesized between the arm common point $(a)$ and a virtual midpoint at the dc-link $(O)$ as in (Fig. 1b)). KVL applied to both upper and lower loops will yield,

$$
\frac{1}{2} V_{x}=v_{1,2}+z i_{1,2} \pm v_{y}
$$

where $z=r+j \omega l$ represents arm impedance, with $r$ as arm equivalent resistance, and $l$ as arm inductance. Now, from the compact-form equations in (3) we multiply the upper and lower arm loops with $i_{1}$ and $i_{2}$ respectively. Hence, we will get power flow equations that relates quantities from the dc-link, arms, and the phases. After rearranging we get,

$$
p_{1,2}=v_{1,2} \times i_{1,2}=\left(\frac{1}{2} V_{x} \mp v_{y}\right)\left(I_{x} \pm \frac{1}{2} i_{y}\right)-p_{z_{1,2}}
$$

with arm power as, $\quad p_{z_{1,2}}=r \cdot i_{1,2}^{2}+l \frac{d i_{1,2}}{d t} i_{1,2}$

In steady state arm power is balanced and contain no dccomponents, thus ripple form of $p_{1,2}$ in (4) is developed as,

$$
\begin{aligned}
\tilde{p}_{1,2} & = \\
& \pm \frac{1}{4} V_{x} \hat{I}_{y} \sin (\omega t-\varphi) \mp \hat{V}_{y} I_{x} \sin (\omega t) \\
& +\frac{1}{4} \hat{V}_{y} \hat{I}_{y} \cos (2 \omega t-2 \varphi)-\tilde{p}_{z_{1,2}}
\end{aligned}
$$

The compact form of $\tilde{p}_{z_{1,2}}$ in (5) can be expressed as,

$$
\begin{aligned}
\tilde{p}_{z_{1,2}} & = \\
& \pm \underbrace{\frac{1}{2} \omega l I_{x} \hat{I}_{y}}_{\hat{p}_{l(w)}} \cos (\omega t-\varphi) \pm \underbrace{r I_{x} \hat{I}_{y}}_{\hat{p}_{r(w)}} \sin (\omega t-\varphi) \\
& +\underbrace{\frac{1}{8} \omega l \hat{I}_{y}^{2}}_{\hat{p}_{l(2 w)}} \sin (2 \omega t-2 \varphi)-\underbrace{\frac{1}{8} \hat{I}_{y}^{2}}_{\hat{p}_{r(2 w)}} \cos (2 \omega t-2 \varphi)
\end{aligned}
$$

Equation (6) shows that power ripple expression $\left(\tilde{p}_{z_{1,2}}\right)$ associated to arm inductance can be neglected in (5) especially for low frequency operation as $\omega$ goes low. This assumption will simplify the relation between phase peak voltage $\left(\hat{V}_{y}\right)$, arm inserted voltage $\left(\hat{e}_{y}\right)$, and the arm peak insertion index $(\hat{m})$ as,

$$
\hat{e}_{y}=\frac{1}{2} \hat{m} V_{x} \simeq \hat{V}_{y}
$$

In a lossless, balanced, and steady state operation, system input-output power balance per MMC phase is achieved, thus,

$$
V_{x} I_{x}=\frac{1}{2} \hat{V}_{y} \hat{I}_{y} \cos \varphi \Longleftrightarrow I_{x}=\frac{1}{4} \hat{m} \hat{I}_{y} \cos \varphi
$$

From (1) and (7), and manipulation of power ripple coefficients in (5) with more significant quantities, we get,

$$
S=\frac{1}{2} \hat{V}_{y} \hat{I}_{y} \Longleftrightarrow \frac{1}{4} V_{x} \hat{I}_{y}=\frac{S}{\hat{m}}
$$

with $S$ being the apparent power per MMC phase. Now, multiplying both sides of (8) with $\hat{V}_{y}$ we get,

$$
\hat{V}_{y} I_{x}=\frac{1}{2} \hat{m} S \cos \varphi
$$

Substituting findings from (9) and (10) in (5) yields,

$$
\begin{aligned}
\tilde{p}_{1,2} & = \\
& \pm \frac{S}{\hat{m}} \sin (\omega t-\varphi) \mp \frac{1}{2} \hat{m} S \cos \varphi \sin (\omega t) \\
& +\frac{1}{2} S \cos (2 \omega t-2 \varphi)
\end{aligned}
$$




\section{EnERgy EQuALIZATION MOdules (EEM)}

A close examination of the arm power ripple expression in (11) reveals that when upper arms are receiving the first harmonic power ripple, lower arms will be delivering the same amount of power in the associated MMC leg, and vice versa. The second harmonic power ripple component however, will be coherently processed by arms of the same leg; i.e. it will be simultaneously absorbed or released within upper or lower arms. This is the natural behavior of arm power when synthesizing phase current $\left(i_{y}\right)$ while being fed by a $d c$-voltage source $V_{x}$. Hence, without further cell ripple minimization techniques such as circulating current and common mode voltage injection cell voltage ripples are induced from buffering arm ripple power quantities. Thus, to reduce cells' voltage ripple we are proposing a method to act upon arm ripple power components themselves. This method is based on the fact of providing an isolated and bidirectional path for the out-of-phase power ripples.

In order to achieve this goal, Energy Equalization Modules (EEM) with isolation bidirectional conversion capability such as the DAhB are to be used. The equivalent model outline of the proposed scheme connecting cells from upper and lower arms is summarized in (Fig. 2) Thus to fully equip an MMC with $2 N$ cells per leg, $N$ plug-in EEMs are needed. Even though EEMs adds more complexity to the already complex system such as the MMC, yet the extended operation limits and reduction in capacitive storage requirements are remarkable. Nevertheless, EEM component sizing and performance improvements will be the focus of future work.

\section{A. Classical Hardware and Control Solutions}

Various hardware and control methods have been proposed to reduce cell voltage ripples, of which include injection of Circulating-Currents (CC), thus increasing losses, and Common-Mode Voltages (CMV) [9], which can be catastrophic as in hazardous areas due to induced sparks in association to bearing currents [10]. Internal quantities manipulation, such as reduction of average arm voltage works till a certain level for low frequency motor drive applications, yet at cost of dynamic response reduction [11]. In addition to the increased losses due to the higher switching requirements, such techniques requires reserving part of the designed rated voltage and current capacity of the system. Thus, leading to system over-rating to accommodate for quantities that will not contribute to the effective energy transfer. One of the hardware methods, propose adding a full-bridge module per arm to compensate for current harmonics and act as an active filter [12], yet the concept is not far from the above mentioned methods as arms has to process the injected quantities, also modularity is scarified.

In this work we introduce a hardware solution that can reduce voltage ripples allowing for low frequency operation by providing an isolated energy path between upper an lower arms. The proposed plug-in module can be integrated into two power modules at early design stages; or as stand alone, i.e. without external supply or communication link with the MMC.

\section{B. Control Method of EEMs}

As the objective is to proof effectiveness of the energy exchange concept at low output frequency using the EEMs,

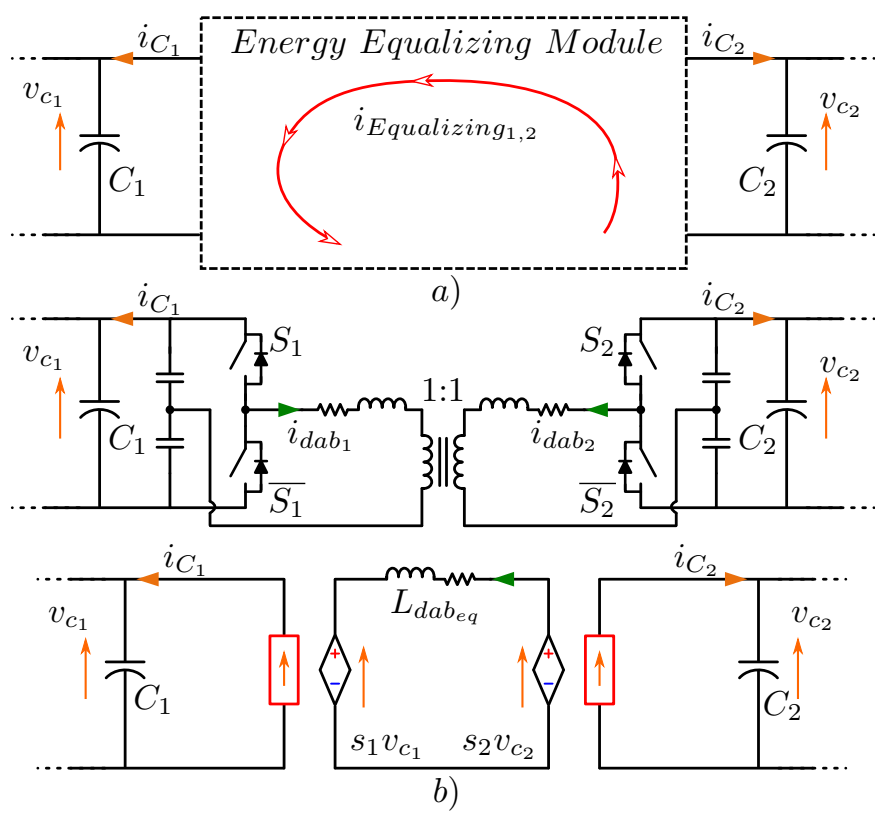

Fig. 2. Energy Equalizing Module (EEM) using a Dual Active half-Bridge (DAhB). a) Schematic. b) Switching model

the high level control is based on energy estimation method as in [13]. From arm current measurements, output power is calculated and arm voltages is estimated on one CPU of the OP4510 system from OPAL-RT. Sorting algorithm [14] and protection schemes are implemented on the FPGA. For the EEM, energy equalization is achieved by adopting a fast current tracking Model Predictive Control (MPC) method on the DAhB. Model used in control and simulation is depicted in (Fig. 2b)). The control concept is based on sharing available energy in two cells. First, the mean voltage of the two cells is set as the reference voltage. Voltage error is then fed into the MPC scheme, where the reference current to be exchanged is calculated. Optimal switching vectors yielding minimum current errors are selected and applied.

The dominant first harmonic current buffered in the equivalent arm cell capacitors is being compensate by the equalizing current induced by the EEM. Thus impressively reducing cell voltage ripples. Although, simulation tests are applied on one equivalent cell per arm, a real system with fast sorting algorithm will achieve a negligible voltage spread among cells of the same arm, hence rendering our assumption for analysis and simulations valid.

\section{MMC-BASED LOW SPEED DRIVES}

In this section the MMC will be used to drive a synchronous motor from stand still up to a speed of $600 \mathrm{rpm}$. Maximum Torque Per Current (MTPC) control method will be adopted to ensure high torque dynamics at low speed.

\section{A. SPMSM Model}

The Surface Permanent Magnet Synchronous Machine (SPMSM) can be modeled as a star-connected three-phase winding, space-displaced by $2 \pi / 3 r d$, as shown in the Fig. 3 . Each phase $x$ can be seen as a series connection of a resistance $R_{x}$ with an inductance $L_{x}$. The electrical equations 
of the SPMSM can be written using the generalized Ohm's and Faraday's laws, under classical assumptions, such as,

$$
\begin{aligned}
& v_{a}=R i_{a}+\frac{d \psi_{a}}{d t} \\
& v_{b}=R i_{b}+\frac{d \psi_{b}}{d t} \\
& v_{c}=R i_{c}+\frac{d \psi_{c}}{d t}
\end{aligned}
$$

with

$$
\begin{aligned}
& \psi_{a}=L i_{a}++\psi_{r} \cos \theta \\
& \psi_{b}=L i_{b}++\psi_{r} \cos \left(\theta-\frac{2 \pi}{3}\right) \\
& \psi_{b}=L i_{b}++\psi_{r} \cos \left(\theta+\frac{2 \pi}{3}\right)
\end{aligned}
$$

where, $v_{x}, i_{x}$ and $\psi_{x}$ are respectively the voltage, current and flux of the phase $x$. Subscripts $a, b$ and $c$ denote the stator phases, whereas $r$ denotes the rotor, and $\theta$ stands for the electrical position of the rotor with respect to the stator. For control purpose, it is a common practice to transform the above equations into a two-phase rotating reference frame ( $d q$-frame). This can be done using the following Park transformation:

$$
\left[\begin{array}{l}
v_{d} \\
v_{q} \\
v_{0}
\end{array}\right]=\frac{2}{3}\left[\begin{array}{ccc}
\cos (\theta) & \cos \left(\theta-\frac{2 \pi}{3}\right) & \cos \left(\theta+\frac{2 \pi}{3}\right) \\
-\sin (\theta) & -\sin \left(\theta-\frac{2 \pi}{3}\right) & -\sin \left(\theta+\frac{2 \pi}{3}\right) \\
\frac{1}{2} & \frac{1}{2} & \frac{1}{2}
\end{array}\right]\left[\begin{array}{l}
v_{a} \\
v_{b} \\
v_{b}
\end{array}\right]
$$

The electrical equations in the rotor $d q$ reference frame are:

$$
\begin{aligned}
& v_{d}=R i_{d}+L \frac{d i_{d}}{d t}-\omega L i_{q} \\
& v_{q}=R i_{q}+L \frac{d i_{q}}{d t}+\omega\left(L i_{d}+\psi_{r}\right)
\end{aligned}
$$

Using this so-called Park model, the SPMSM control can be made as handy as the conventional DC machines control. The direct $d$ axis is aligned to the rotor flux vector, it is thus the flux producing axis. The axis $q$ is in quadrature with the $d$ axis, and it is the torque-producing axis (Fig. 3). This control structure is often referred to as the vector control, or the field-oriented control.

\section{B. Maximum Torque Per Current Control}

The Maximum Torque Per Current (MTPC) control consists of choosing the $d q$ currents set-points that realize the requested torque, minimize the total current in the machine and respect the voltages and currents limits. The torque equation in the $d q$ coordinates is:

$$
T_{m}=\frac{3}{2} p \psi_{r} i_{q}
$$

Without constraints, the requested torque $T_{m}^{*}$ can be achieved by tuning the $q$-axis current set-point, $i_{q}^{*}$ to:

$$
i_{q}^{*}=\frac{2}{3} \frac{T_{m}^{*}}{p \psi_{r}}
$$

The total current $I=\sqrt{i_{d}^{2}+i_{q}^{2}}$ can be minimized by tuning $i_{d}^{*}$ to zero. Therefore the MPTC trajectory, in the $\left(i_{d}, i_{q}\right)$ plane is simply the line described by the equation $i_{d}=0$.

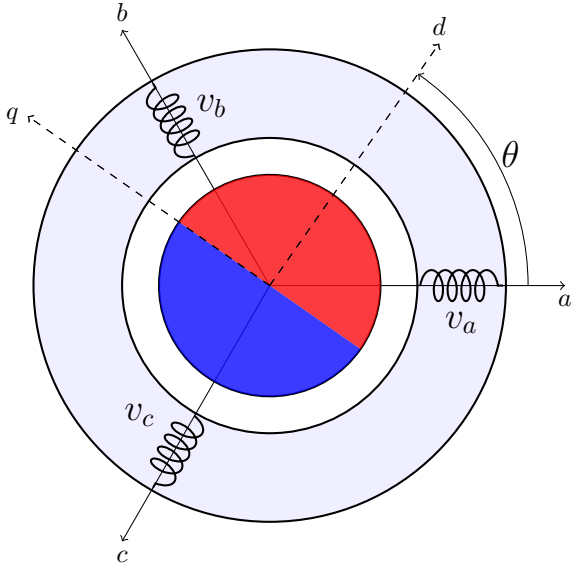

Fig. 3. Schematic representation of the SPMSM

For safety reasons, the current $I$ is limited to a certain $I_{\max }$. The maximum current operating condition is described by:

$$
i_{d}^{2}+i_{q}^{2}=I_{\max }^{2}
$$

In the $\left(i_{d}, i_{q}\right)$ plane, this give a circle, centered at the origin, with a radius $I_{\max }$. The circle equation can be written as:

$$
i_{q}= \pm \sqrt{I_{\text {max }}^{2}-i_{d}^{2}}
$$

Furthermore, the input voltage cannot get higher than the DCbus voltage, therefore, the voltages are limited to a certain $V_{\text {max }}$, such that the maximum voltage operation is described by:

$$
v_{d}^{2}+v_{q}^{2}=V_{\max }^{2}
$$

In order to illustrate the voltage constraints in the $\left(i_{d}, i_{q}\right)$ plane, the steady-state voltage equations are considered, and the resistive voltage drop is neglected as the speed is considered high (no voltage constraints at low speed):

$$
\left(-\omega L i_{q}\right)^{2}+\left(\omega L i_{d}+\omega \psi_{r}\right)^{2}=V_{\max }^{2}
$$

This gives another circle, centered at $\left(\frac{-\psi_{r}}{L}, 0\right)$, with a speeddependent radius $\frac{V_{\max }^{2}}{\omega^{2} L^{2}}$; the higher the speed, the lower the radius:

$$
i_{q}= \pm \frac{1}{L} \sqrt{\frac{V_{\max }^{2}}{\omega^{2}}-\left(L i_{d}+\psi_{r}\right)^{2}}
$$

These voltage and current limitations decides the upper limit of the requested torque, and modifies the MTPC trajectory when operating at speeds higher than the rated speed: it is shown on Fig. 4 that, inside the disc of admissible currents, a requested torque, represented by a torque-invariant horizontal line, can be achieved using several combinations of $i_{d}^{*}$ and $i_{q}^{*}$. When the motor speed gets higher than the rated speed, the voltage circle imposes a negative $i_{d}^{*}$ on the MTPC trajectory, called the field weakening trajectory:

$$
i_{d}^{*}<0
$$

The optimal field weakening trajectory corresponds to the set of intersection points between currents and voltages circles 
that minimize the current vector and maximize the toque. This trajectory is shown on the Fig. 4 for $\frac{\psi_{r}}{L} \geq I_{\max }$ and on Fig. 5 for $\frac{\psi_{r}}{L} \leq I_{\max }$.

In practice, this trajectory cannot be perfectly known, it is sufficient to choose a certain negative set-point for $i_{d}$, depending on the motor speed.

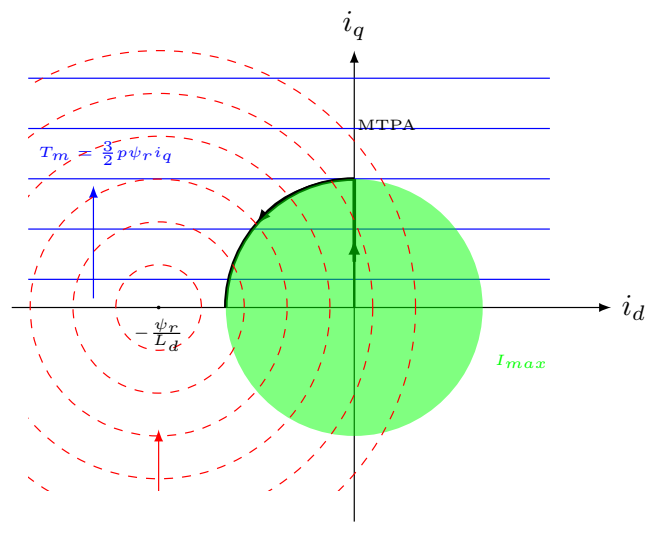

Fig. 4. MTPC Curve Schematic

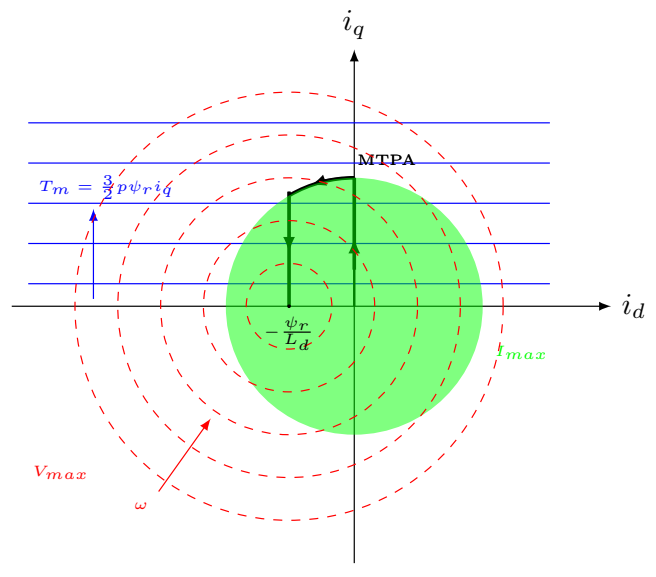

Fig. 5. MTPC Control Curve

\section{Simulation Results}

The effectiveness of the proposed EEM-cells is validated throughout two low frequency test. The first, was performed at a fixed insertion index $(\hat{m})$ and frequency $(\omega)$. The second test, validated low frequency operation of MMC in motor drive applications. Motor drive applications of a PMSM using MMC was tested. (Fig. 6) shows the simulation results of a PMSM driven by a MMC from standstill till a speed of $600 \mathrm{rpm}$, reached at $t=1.4[\mathrm{sec}]$. Along with the frequency sweep, the insertion index is gradually increased from 0 at $t=0$ till $85 \%$ at $t=1.2[\mathrm{sec}]$. The MMC driving a 4 poles PMSM is fed by a $400 \mathrm{~V}$ dc link. (Fig. 6-a and -b) shows the upper and lower arm inserted and available voltages of phase-a. Voltage ripple is worst for the lowest frequencies. At $t=1.8[\mathrm{sec}]$ the EEMs were engaged in the ripple reduction process. The effectiveness of ripple reduction is clear and shows more than $60 \%$ ripple reduction. Phase currents $\left(i_{y}\right)$ and arm circulating currents $\left(i_{c}\right)$ are depicted in (Fig. 6-c). The engagement of EEMs remarkably reduces circulation currents due to the reduction of arm available voltages. In order to totally eliminate circulating currents, further suppression methods can be included in the control algorithm. The power components delivered to the driven machine are depicted in (Fig. 6-d)

\section{CONCLUSION}

A plug-in module introduced in this work will greatly reduce cells capacitor voltage ripple in MMC operating at low output frequency, such as in high-torque motor drive applications. This will allow MMC structures to operate at low frequency with lower voltage ripples without over-rating converter components, producing additional losses due to circulating currents, and risking common mode voltages wellknow problems in motor drive applications. The introduced method impressively reduce energy storage requirements, thus reducing size and cost of capacitors. Future work aims to quantify the introduced benefits of the system by showing the percentage of ripple reduction and the required rating of the plug-in modules.

\section{REFERENCES}

[1] H. Abu-Rub, M. Malinowski, and K. Al-Haddad, Power Electronics for Renewable Energy Systems, Transportation and Industrial Applications. John Wiley \& Sons, 2014.

[2] M. A. Perez, S. Bernet, J. Rodriguez, S. Kouro, and R. Lizana, "Circuit topologies, modeling, control schemes, and applications of modular multilevel converters," IEEE Transactions on Power Electronics, vol. 30, no. 1 , pp. 4-17, 2015

[3] M. Sleiman, A. Al Hage Ali, H. F. Blanchette, K. Al-Haddad, B. Piepenbreier, and $\mathrm{H}$. Kanaan, "A survey on modeling, control, and dc-fault protection of modular multilevel converters for hvdc systems," in IEEE 23rd International Symposium on Industrial Electronics (ISIE), 2014, pp. 2149-2154.

[4] M. Sleiman, H. F. Blanchette, K. Al-Haddad, L. A. Gregoire, and H. Y. Kanaan, "A new 71-puc multi-cells modular multilevel converter for ac-ac and ac-dc applications," in IEEE International Conference on Industrial Technology (ICIT), 2015.

[5] R. Marquardt, A. Lesnicar, and J. Hildinger, "Modulares stromrichterkonzept fr netzkupplungsanwendung bei hohen spannungen," in ETG-Fachtagung, 2002.

[6] A. Lesnicar and R. Marquardt, "An innovative modular multilevel converter topology suitable for a wide power range," in Power Tech Conference Proceedings, 2003 IEEE Bologna, vol. 3, p. 6 pp. Vol.3.

[7] J. Dorn, H. Gambach, J. Strauss, T. Westerweller, and J. Alligan, "Trans bay cable-a breakthrough of vsc multilevel converters in hvdc transmission," in Cigre Colloquium, 2012.

[8] Siemens, "Sm120 cabinet modules catalog," [Online]. Available: https: //mall.industry.siemens.com/mall/en/WW/Catalog/Products/10228063, [accessed 15-January-2016].

[9] A. J. Korn, M. Winkelnkemper, and P. Steimer, "Low output frequency operation of the modular multi-level converter," in Energy Conversion Congress and Exposition (ECCE), 2010 IEEE, pp. 3993-3997.

[10] S. Kanerva, S. Bono, B. Oberbauer, H. Persson, and G. Scheuer, "Motor design considerations for medium voltage adjustable speed drive systems in hazardous areas," in Petroleum and Chemical Industry Conference (PCIC), 2010 Record of Conference Papers Industry Applications Society 57th Annual, pp. 1-8.

[11] A. Antonopoulos, L. Angquist, S. Norrga, K. Ilves, L. Harnefors, and H. P. Nee, "Modular multilevel converter ac motor drives with constant torque from zero to nominal speed," IEEE Transactions on Industry Applications, vol. 50, no. 3, pp. 1982-1993, 2014.

[12] B. S. Riar and U. K. Madawala, "Decoupled control of modular multilevel converters using voltage correcting modules," IEEE Transactions on Power Electronics, vol. 30, no. 2, pp. 690-698, 2015. 


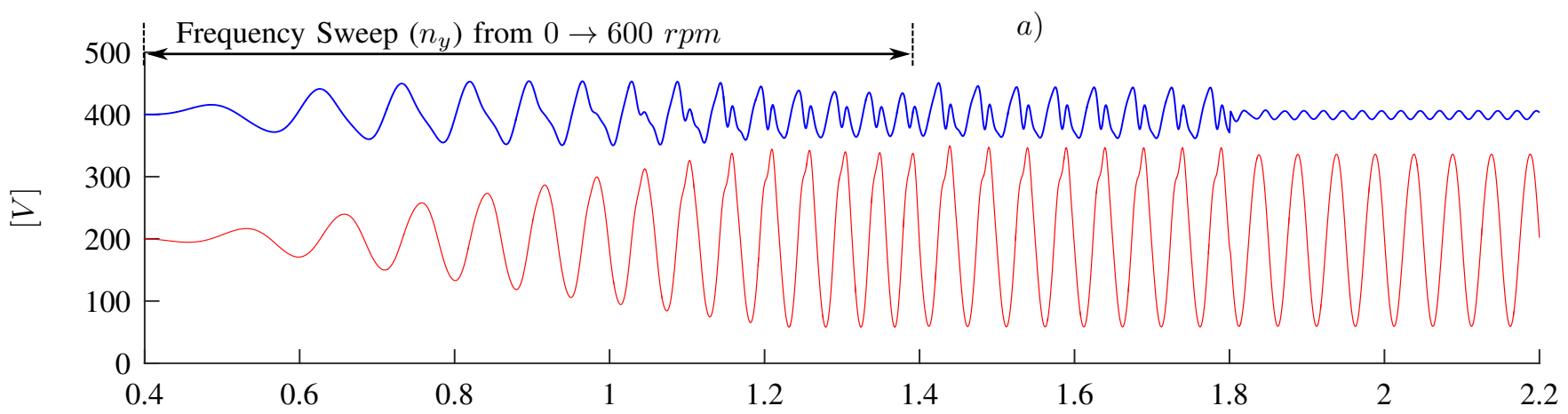

b)
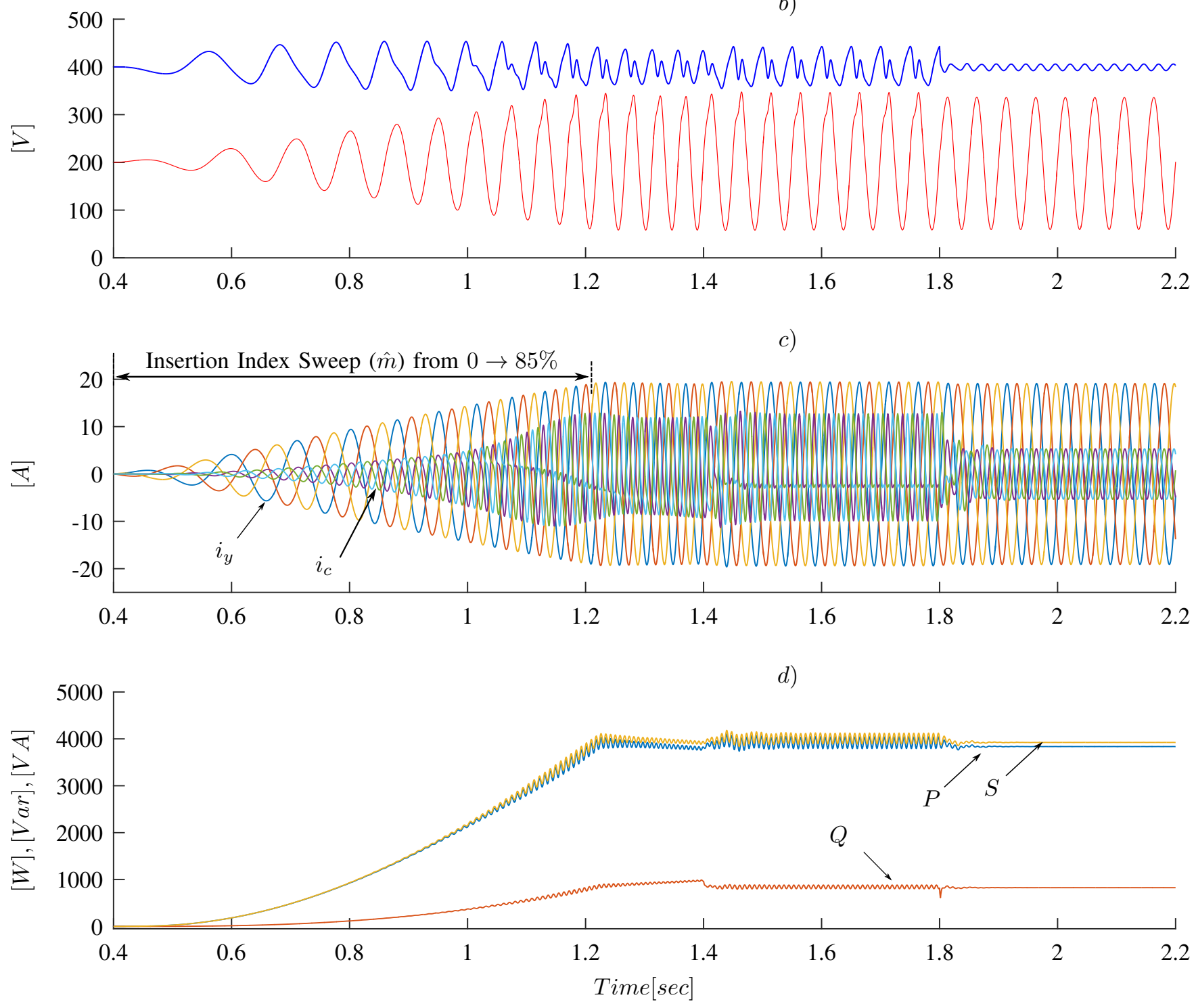

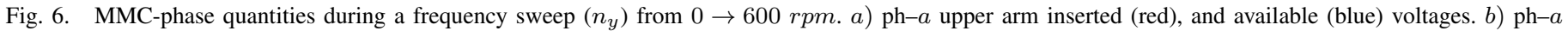

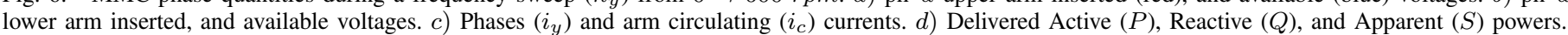

[13] L. Angquist, A. Antonopoulos, D. Siemaszko, K. Ilves, M. Vasiladiotis, and H. P. Nee, "Open-loop control of modular multilevel converters using estimation of stored energy," IEEE Transactions on Industry Applications, vol. 47, no. 6, pp. 2516-2524, 2011.
[14] M. Glinka and R. Marquardt, "A new ac/ac multilevel converter family," IEEE Transactions on Industrial Electronics, vol. 52, no. 3, pp. 662669, 2005. 